\title{
0 referencial freireano e as pesquisas sobre formação inicial de professores na área das ciências da natureza: considerações iniciais
}

\author{
Freirean framework in science teacher education researches: early \\ considerations
}

\author{
Pedro Neves da Rocha ${ }^{1}$ \\ Renato Eugênio da Silva Diniz²
}

\begin{abstract}
Resumo
Este trabalho consistiu na caracterização geral das inserções da perspectiva freireana em pesquisas sobre formação inicial de professores das ciências da natureza (EC), focalizada em 16 artigos publicados de 2010 a 2020, e 21 teses e dissertações publicadas entre 2015 e 2020. A partir da Análise de Conteúdo, as unidades foram levantadas e analisadas por três processos: quantificação das menções nos artigos; levantamento das seções de teses e dissertações com menções a Freire; e categorização das menções nas dimensões ontológica, gnosiológica, metodológica, e transformação da realidade. Como resultados, evidenciamos que metade dos artigos trouxe até 5 menções ao referencial. Para as teses e dissertações, observamos que 21 pesquisas mencionaram Freire nas seções introdutórias, enquanto 17 também utilizaram seu referencial em discussões e conclusões, e 9 também basearam suas metodologias na perspectiva freireana. Ademais, notamos que a dimensão ontológica apareceu em todos os trabalhos, seguida da dimensão de transformação da realidade (em 30 pesquisas), gnosiológica (24) e metodológica (19). Assim, concluímos ser urgente uma maior aproximação do referencial freireano à formação de professores do EC, principalmente em âmbito metodológico.
\end{abstract}

Palavras-chave: Paulo Freire. Ensino de ciências. Formação de professores. Formação inicial docente. Revisão bibliográfica.

\begin{abstract}
This paper consisted of a general characterization of the insertions of the Freirean perspective in research on natural science teacher's initial training, focused on 16 articles published from 2010 to 2020, and 21 theses and dissertations published between 2015 and 2020. Based on Content Analysis, the units were analyzed by three processes: quantification of mentions in the articles; exploration of theses' and dissertations' sections with references to Freire; and categorization of mentions into ontological, gnosiological, methodological and reality transformation dimensions. As a result, we
\end{abstract}

\footnotetext{
${ }^{1}$ Doutorando em Educação para a Ciência - Faculdade de Ciências de Bauru/SP - Universidade Estadual Paulista "Júlio de Mesquita Filho". E-mail: pedro.n.rocha@unesp.br

${ }^{2}$ Professor Adjunto do Departamento de Ciências Humanas e Ciências da Nutrição e Alimentação - Instituto de Biociências de Botucatu/SP - Universidade Estadual Paulista "Júlio de Mesquita Filho". Email: renato.es.diniz@unesp.br
} 


\section{-Revista de Iniciação à Docência, v.6, n.2, 2021- Publicação: dezembro, 2021 - ISSN 2525-4332}

show that half of the articles brought up to 5 mentions to the framework. For theses and dissertations, we observed that 21 researches mentioned Freire in the introductory sections, while 17 also used his framework in discussions and conclusions, and 9 also based their methodologies on the Freirean perspective. Furthermore, we note that the ontological dimension appeared in all researches, followed by the dimensions of reality transformation (30 studies), gnosiological (24) and methodological (19). Thus, we conclude that it is to bring the Freirean framework closer to teacher training in the natural sciences, in its diversity of aspects, mainly in the methodological scope.

Keywords: Paulo Freire. Science teaching. Teacher education. Preservice teacher training. Literature survey.

\section{Introdução}

Este trabalho consiste em um breve levantamento bibliográfico de pesquisas recentes na área de formação inicial de professores da área de Ensino de Ciências da Natureza (EC). A opção pela delimitação na intersecção destas áreas específicas justificase pelo fato de que este levantamento consistiu em uma etapa inicial de uma pesquisa de doutorado, voltada a formação inicial de professores de ciências da natureza orientada pela perspectiva freireana (FREIRE, 1978, 1992, 2000, 2007, 2011, 2014).

Consideramos importante e necessária essa aproximação, uma vez que a formação de professores - especialmente na área do EC - é tomada por uma perspectiva de racionalidade técnica. Ao longo do século XX, de acordo com Nardi e Cortela (2015) e Saviani (2002, 2005, 2007, 2011), é possível notar diversas tendências em disputa de interesses e poderes: concepções tradicionais, ou pragmáticas "renovadas", concepções não-críticas e críticas, hegemônicas e contra hegemônicas. No caso da educação brasileira, também é marcante um dualismo entre a escola proposta às elites, e a escola (ou sua ausência) destinada às classes trabalhadoras (MOREIRA, 1992; SAVIANI, 2002, 2005, 2007, 2011; MARCÍLIO, 2005; VECHIA, 2005; FREITAS; BICCAS, 2009; LIBÂNEO, 2012; BARCELOS, 2017; BOURDIEU, 2017).

Além disso, diversos autores desvelaram como os interesses do mercado financeiro e da ideologia capitalista contemporânea estiveram presentes e se intensificaram ao intervir na educação brasileira, especialmente a partir da metade do século XX e na redemocratização neoliberal. Deste processo de racionalização instrumental, a carreira docente foi cada vez mais proletarizada (FREIRE, 1992, 2007, 2011, 2014; ALTMANN, 2002; CONTRERAS, 2002; DUARTE, 2003; BASTOS et al., 2011; SAVIANI, 2011; LIBÂNEO, 2012; LEMES, 2013; CHASTEEN, 2016; GIMENES, 2016; NARDI; CORTELA, 2015; SGUISSARDI, 2015).

Neste contexto, se faz necessário desenvolver um processo formativo de professores que vise superar tais visões distorcidas do trabalho científico, e promover a 
apropriação de princípios, metodologias e estratégias de ensino diversificadas. Dentre elas, consideramos a Educação Libertadora, em uma perspectiva freireana (FREIRE, 1978, 1992, 2000, 2007, 2011, 2014) como de grande potencial para contribuir com a superação da problemática abordada neste projeto.

A Educação Libertadora freireana está apoiada na perspectiva da problematização e dialogicidade, sob um viés crítico-transformador. Para o autor (FREIRE, 2011), a problematização é o processo que visa a superação de uma situação-limite. Esta, por sua vez é a própria condição de dominação dos sujeitos; são as fronteiras entre o ser e o ser mais. Freire (2011) denomina esse processo como humanização (em contraposição à hominização, que é o condicionamento às situações de opressão).

Por esse motivo, compreendemos que uma educação crítica está sempre alinhada ao objetivo de transformação da realidade. O autor distingue a espécie humana dos outros animais a partir da indissociabilidade de nossa atividade transformadora e nossa historicidade, a consciência de nossa atividade e de suas finalidades. Neste contexto, a humanização mostra-se como um processo dialógico, problematizador e crítico. Por estar baseado nesses preceitos, Freire (Ibid.) considera que o processo histórico de humanização dos oprimidos é justamente a subversão, a libertação.

Mais além, o autor afirma que este processo deve ocorrer de maneira coletiva. Segundo Freire (2011, p. 71), "ninguém liberta ninguém, ninguém se liberta sozinho: os homens se libertam em comunhão" (FREIRE, 2011, p. 71). Somado a isso, "não há diálogo verdadeiro se não há nos seus sujeitos um pensar verdadeiro. Pensar crítico." (FREIRE, 2011, p. 114). Através do diálogo, é possível promover o compartilhamento da visão de mundo de cada sujeito, a qual reflete a posição e situação de cada um no mundo.

Freire (Ibid.) considera, ainda, que tal transformação é dialética, pois ocorre através da práxis: apropriação e produção de conhecimentos teóricos articulados às ações práticas. Para o autor, portanto, as situações-limite consistem em problemas que exigem respostas em nível intelectual e prático. Por ser dialético, esse movimento é dinâmico: origina-se no todo, direciona-se à parte, e retorna ao todo. Parte do concreto, caminha para o abstrato e retorna ao concreto.

Em relação à formação de professores, consideramos que é importante promover no momento de formação inicial uma experiência concreta de uma educação crítica. Assim, o objetivo deste levantamento consiste em inferir as relações estabelecidas e explorações realizadas entre a perspectiva freireana e a formação inicial de professores, em publicações recentes. Dessa maneira, é possível compreendermos as diferentes abordagens realizadas por pesquisadores, buscando reforçar e expandir pontos frutíferos para o desenvolvimento das pesquisas neste recorte de área. Por outro lado, a partir do levantamento é possível explicitarmos pontos que necessitem de maior aprofundamento e maior exploração. 


\section{Metodologia}

Para este levantamento foi utilizado o Portal de Periódicos da Coordenação de Aperfeiçoamento de Pessoal de Nível Superior (CAPES) (BRASIL, 2020), limitado por nós exclusivamente a artigos. A partir dos descritores "Freire" e "formação professores", delimitado o período entre 2010 e 2020, foram encontrados inicialmente 1074 artigos. Já para as teses e dissertações, utilizamos a Biblioteca Digital de Teses e Dissertações (BDTD) do Instituto Brasileiro de Informação em Ciência e Tecnologia (IBICT). A partir dos descritores "Paulo Freire", "Professores - Formação" 3 ; "Ensino de Ciências", encontramos 437 publicações de diversas áreas. A partir dos resultados, foram lidos os títulos, resumos, referenciais, e quando necessário partes do corpo dos textos integrais. Após a triagem, foram selecionados 16 artigos, 11 dissertações e 10 teses que encontravam-se especificamente dentro da área de ensino das ciências da natureza (biologia, física e química), ao mesmo tempo que voltavam-se à formação inicial de professores.

Para análise dos trabalhos encontrados, utilizamos a Análise de Conteúdo. Esta consiste em uma técnica quali-quantitativa de tratamento de dados escritos ou gráficos, criada no contexto nos anos de 1940 para análise de mídias e políticas no contexto bélico (BARDIN, 1977). Posteriormente, a técnica migrou para a academia, onde sofreu reflexões críticas e extrapolou seu caráter instrumental inicial (CARLOMAGNO; ROCHA, 2016). Em suma, a Análise de Conteúdo ocorre via: desmontagem de um enunciado (descontextualizado também das condições de produção); definição de unidades de registro, unidades de contexto e unidades de enumeração; categorização de forma $a$ priori, a posteriori ou mista (VALA, [s.d]).

Reconhecemos a limitação qualitativa desta técnica, dada sua fundamentação numa visão analítico-objetivista. Neste caso, a Análise de Conteúdo parte do pressuposto que elementos do enunciado podem ser compreendidos de forma pura, totalmente alienados entre si e de seu contexto. Tal concepção pode resultar em certos conflitos com um paradigma crítico-dialético, como a perspectiva freireana. Tal conflito manifestou-se, por exemplo, na categorização de unidades deste trabalho, que de fato não são independentes para Freire, mas sim, fazem parte de um todo sistêmico, com significado residente na síntese dos elementos.

Mesmo assim, considerando estas limitações e ressaltando que nossa categorização reconhece a interdependência dos elementos, analisamos as diversas menções à perspectiva freireana contidas nos artigos encontrados, quantificamos e

\footnotetext{
3 Ratificamos o uso apenas do descritor "Professores - Formação", e não utilização de outros termos recorrentes na área (tais como "formação docente" e semelhantes) pois o sistema de buscas do BDTD possui descritores pré-determinados no campo "assunto", justamente para garantir que pesquisas de mesmo tópico fiquem interligadas no Banco de Dados.
} 
classificamos as mesmas segundo eixos do pensamento de Paulo Freire (a partir das unidades de registro, contexto e enumeração) em 4 categorias: Dimensão ontológica; Dimensão gnosiológica; Dimensão metodológica; Dimensão Transformação da realidade. 0 processo de criação das categorias foi realizado a posteriori. Ou seja, após a leitura de todos trabalhos, elaboramos as categorias a partir de pontos centrais evidenciados naqueles.

A categoria de Dimensão ontológica abarcou unidades que diziam respeito às atitudes dos sujeitos. Por exemplo, postura crítica, dialógica, problematizadora, participativa, afetiva, humilde, relações interpessoais, dentre outras. Já a categoria Dimensão gnosiológica abarcou princípios freireanos relativos à natureza do conhecimento. Por exemplo natureza coletiva, colaborativa, dialética, interdisciplinar, histórica, contraditória, materialista do conhecimento. Em terceiro lugar, foi elaborada a categoria de Dimensão metodológica. Esta reuniu unidades relacionadas com o processo de ensino e de aprendizagem propriamente dito. Como exemplo, podemos indicar a Investigação Temática e Temas Geradores (FREIRE, 1978, 1992, 2000, 2007, 2011, 2014).

Por fim, foi elaborada a categoria Transformação da realidade. Nela, foram incluídas críticas e denúncias sobre a sociedade (tais como as condições de dominação, a educação bancária), além de maneiras e anúncios de superação de tais contradições e opressões (FREIRE, 2011). Ressaltamos que as unidades de registro e contexto abarcadas nesta categoria poderiam ter sido classificadas em quaisquer outras. Entretanto, a opção por discriminar esta categoria se deu ao fato de que, apesar de a proposição de transformação da realidade e emancipação coletiva dos sujeitos ser uma parte essencial e inalienável da perspectiva freireana (FREIRE, 1978, 1992, 2000, 2007, 2011, 2014), não foram em todos os casos que esse compromisso - essência de qualquer pedagogia crítica - se fez presente. Assim, a discriminação desta categoria visou justamente buscar a presença explícita do viés crítico e transformador da Pedagogia Libertadora nos trabalhos.

\section{Resultados e Discussão}

Para facilitar a apresentação dos dados, os artigos foram correlacionados com códigos de A1 a A16 para artigos, D1 a D11 para dissertações e T1 a T10 para teses, apresentados na Quadro 1.

Quadro 1: Correlação entre códigos, publicações e disciplinas

\begin{tabular}{|l|l|l|l|l|l|}
\hline Área & Cód. & Referência & Área & Cód. & Referência \\
\hline Biologia & A1 & Lima; Ferreira (2018) & Química & D6 & Ferreira (2015) \\
\cline { 2 - 3 } & A2 & Morais; Albino (2015) & & D7 & Mori (2019) \\
\cline { 2 - 3 } \cline { 5 - 6 } & D1 & Oliveira (2016) & & D8 & Tadeu (2018) \\
\hline
\end{tabular}


Publicação: dezembro, 2021 - ISSN 2525-4332

\begin{tabular}{|c|c|c|c|c|c|}
\hline & $\mathrm{D} 2$ & Mackeivicz (2017) & & D9 & Silva (2018) \\
\hline & T1 & Araújo (2018) & & T3 & Nogueira (2018) \\
\hline \multirow[t]{7}{*}{ Física } & A3 & Gelhen et al. (2016) & & T4 & Gondim (2019) \\
\hline & A4 & Roso et al. (2015) & & T5 & Rigue (2020) \\
\hline & A5 & Watanabe-Caramello et al., (2012) & & T6 & Leite (2015) \\
\hline & A6 & Costa Junior et al., (2019) & \multirow{10}{*}{$\begin{array}{l}\text { Ciências } \\
\text { da } \\
\text { Natureza }\end{array}$} & A13 & Nicolodi; Silva (2016) \\
\hline & D3 & Vieira (2018) & & A14 & Rezende; Ostemann (2020) \\
\hline & D4 & Vargas (2018) & & A15 & Lima et al. (2020) \\
\hline & $\mathrm{T} 2$ & Cardoso (2019) & & A 16 & Neres; Gehlen (2018) \\
\hline \multirow[t]{7}{*}{ Química } & A7 & Gonçalves et al. (2012) & & D10 & Salgueiro (2019) \\
\hline & A8 & Brito et al (2012) & & D11 & Guaita (2015) \\
\hline & A9 & Pinto; Maciel (2014) & & $\mathrm{T7}$ & Dalmolin (2020) \\
\hline & A10 & Silveira; Zanetic (2016) & & $\mathrm{T} 8$ & Gimenes (2016) \\
\hline & A11 & Altarugio; Varone (2016) & & T9 & Cunha (2017) \\
\hline & $\mathrm{A} 12$ & Weber et al. (2012) & & T10 & Melo (2019) \\
\hline & D5 & Martins (2016) & & & \\
\hline
\end{tabular}

Fonte: Elaborado pelos autores.

O Quadro 1 foi organizado da seguinte maneira. A partir da leitura dos elementos pré-textuais das pesquisas (título, resumo, entre outros), foi inferida a área focalizada em cada uma delas. Diversas vezes, esta foi condicionada ao próprio curso abarcado em cada trabalho (por exemplo, licenciatura em ciências biológicas, licenciatura em física, etc.). Já os trabalhos considerados como parte da área "Ciências da Natureza" consistiram em pesquisas que abordaram diversos cursos ao mesmo tempo, como, por exemplo, as pesquisas de Salgueiro (2019) e Gimenes (2016), que contaram com a participação de licenciandos em física, biologia e química.

Já no Quadro 2, apresentamos o levantamento da incidência do pensamento freireano nas pesquisas. Em relação aos artigos, foram quantificadas as menções a Paulo Freire ao longo de cada publicação. Além disso, tanto para os artigos como para as teses e dissertações, contabilizamos a diversidade de categorias às quais as menções ao referencial freireano presentes nas pesquisas foram classificadas. Assim, buscamos analisar o grau de presença e diversidade da mobilização do referencial freireano na seleção de trabalhos. 
-Revista de Iniciação à Docência, v.6, n.2, 2021-

Publicação: dezembro, 2021 - ISSN 2525-4332

Quadro 2: Incidência do pensamento freireano nas publicações

\begin{tabular}{|l|l|l|l|l|l|}
\hline $\begin{array}{l}\text { Quantidade } \\
\text { de inserções }\end{array}$ & Artigos & $\begin{array}{l}\text { Total de } \\
\text { artigos }\end{array}$ & $\begin{array}{l}\text { Diversidade } \\
\text { de inserções }\end{array}$ & Publicações & $\begin{array}{l}\text { Total de } \\
\text { trabalhos }\end{array}$ \\
\hline Entre 1 e 5 & $\begin{array}{l}\text { A1, A2, A3, A8, A9, A11, } \\
\text { A14, A15. }\end{array}$ & 8 & 1 categoria & A7, A12, D1, T3 & 4 \\
\hline Entre 6 e 10 & A5, A6, A11. & 3 & 2 categorias & A1, A3, A8, A11, D5, D6. & 6 \\
\hline Entre 11 e 15 & A13. & 1 & 3 categorias & $\begin{array}{l}\text { A2, A6, A9, A13, A14, } \\
\text { D2, D3, D7, D9, D10, T2, } \\
\text { T5, T8. }\end{array}$ & 13 \\
\hline Mais de 15 & A4, A7, A9, A16. & 4 & 4 categorias & $\begin{array}{l}\text { A4, A5, A7, A9, A15, } \\
\text { A16, D4, D8, D11, T1, T4, } \\
\text { T6, T7, T9, T10 }\end{array}$ & 15 \\
\hline
\end{tabular}

Fonte: Elaborado pelos autores.

Essa busca foi justificada pelo fato de que notamos que alguns trabalhos utilizaram-se deste referencial de forma pontual - seja apenas como poucas ou até uma única citação isolada; seja abordando apenas alguma dimensão categorizada (normalmente, a ontológica). Esta constatação apoia-se também em outras pesquisas mais amplas de estado da arte (VIVEIRO et al., 2015; ZANCUL et al., 2015; ZANCUL; VIVEIRO, 2017, 2019; PIERONI et al., 2019), que notaram em diferentes recortes temporais e de área - a partir de 2008, em artigos do EC e da Educação Ambiental - semelhante lacuna na apropriação do referencial freireano. Após o levantamento, constatamos que em nossa seleção, metade dos artigos trouxeram até 5 menções ao autor. Em alguns casos, houve apenas uma única citação isolada. Além disso, constatamos que a diversidade do pensamento freireano também não foi tão abordada por quase 1/4 das publicações, que se ativeram apenas a uma ou duas categorias.

No Quadro 3, a seguir, apresentamos as seções das teses e dissertações em que o referencial freireano é utilizado.

Quadro 3: Seções em que o referencial freireano é abordado.

\begin{tabular}{|l|l|l|}
\hline Seções & Publicações & $\begin{array}{l}\text { Total de } \\
\text { trabalhos }\end{array}$ \\
\hline $\begin{array}{l}\text { Introdução e } \\
\text { fundamentação teórica }\end{array}$ & $\begin{array}{l}\text { D1, D2, D3, D4, D5, D6, D7, D8, D9, D10, D11, T1, T2, T3, T4, T5, T6, } \\
\text { T7, T8, T9, T10 }\end{array}$ & 21 \\
\hline Discussão e conclusão & D2, D3, D4, D5, D8, D9, D10, D11, T1, T2, T3, T4, T5, T6, T7, T9, T10 & 17 \\
\hline Metodologia & D3, D4, D8, D10, T1, T4, T6, T9, T10 & 9 \\
\hline
\end{tabular}

Fonte: Elaborado pelos autores.

Em relação às menções ao autor nas seções das teses e dissertações, todas as pesquisas fizeram referências a Freire nas seções introdutórias. Já 17 pesquisas também o trouxeram nas discussões e conclusões. Entretanto, apenas 9 pesquisas trouxeram o autor na seção de métodos. Assim, consideramos que há um distanciamento entre Freire e as metodologias das pesquisas do recorte definido. Portanto, julgamos importante que a questão metodológica seja explorada em maior profundidade, uma vez que a própria noção de pesquisa e ensino para Freire (2011) relaciona-se ao conceito de práxis, ou seja, a 


\section{-Revista de Iniciação à Docência, v.6, n.2, 2021- Publicação: dezembro, 2021 - ISSN 2525-4332}

unidade dialética entre teoria e prática. Assim, condiz com o referencial que as pesquisas concretizem nas práticas investigativas os princípios desenvolvidos pelo autor.

Acerca da elaboração das categorias a partir da análise das unidades, ressaltamos que elencamos unidades de registro semânticas e não formais. Ou seja, buscamos inferir o significado das unidades dentro da sua unidade de contexto, não focando apenas na forma (palavra em si). Isso se deve ao fato de que há, por um lado, uma polissemia de termos, bem como existem, por outro lado, sinônimos ou inflexões para uma mesma ideia. No Quadro 4 são apresentadas todas as unidades de registro elencadas para cada categoria. Já no Quadro 5, em sequência, apresentamos as publicações com menções ao pensamento freireano (FREIRE, 1978, 1992, 2000, 2007, 2011, 2014) classificados em cada categoria.

Quadro 4: Unidades de registro elencadas para cada categoria

\begin{tabular}{|l|l|}
\hline Categoria & Unidades de registro \\
\hline Dimensão ontológica & $\begin{array}{l}\text { Reflexão, pensamento crítico; relação social; relação dialética entre } \\
\text { educador-educando; colaboração; democratização; participação; tomada } \\
\text { de decisão; contextualização; politização; práxis; problematização; } \\
\text { autonomia; pedagogia da pergunta; pedagogia da escuta; diálogo; } \\
\text { dialogicidade. }\end{array}$ \\
\hline $\begin{array}{l}\text { Transformação da } \\
\text { realidade }\end{array}$ & $\begin{array}{l}\text { Formação crítica; curiosidade ingênua e curiosidade epistemológica; } \\
\text { superação de senso comum; inédito viável; transformação da realidade; } \\
\text { consciência mágica, ingênua e reflexiva; consciência real e consciência } \\
\text { possível; libertação; emancipação; superação de dominação/da } \\
\text { opressão/da desigualdade; relação opressor-oprimido; passividade; } \\
\text { transmissão; imposição; formar X treinar; ensinar X transferir; educação } \\
\text { bancária; hominização/desumanização; cultura do silêncio. }\end{array}$ \\
\hline Dimensão metodológica & $\begin{array}{l}\text { Problematização; temas geradores; palavra geradora; círculo de cultura; } \\
\text { abordagem temática; análise da realidade; codificação; situação-limite; } \\
\text { teorização; diálogos descodificadores; sistematização; redução temática; } \\
\text { estrutura vertical e horizontal do conhecimento. }\end{array}$ \\
\hline Dimensão gnosiológica & $\begin{array}{l}\text { Construção coletiva, colaborativa, dialógica, dialética; dialética entre } \\
\text { ensinar-aprender; interdisciplinaridade; historicidade; contradição; } \\
\text { materialidade do conhecimento; incompletude do saber; rigorosidade } \\
\text { metódica. }\end{array}$ \\
\hline
\end{tabular}

Fonte: Elaborado pelos autores. 
Quadro 5: Categorização das menções nas publicações analisadas

\begin{tabular}{|l|l|l|}
\hline Categoria & Publicações & $\begin{array}{l}\text { Total de } \\
\text { trabalhos }\end{array}$ \\
\hline Dimensão ontológica & $\begin{array}{l}\text { A1, A2, A3, A4, A5, A6, A7, A8, A9, A10, A11, A12, A13, A14, A15, } \\
\text { A16, D1, D2, D3, D4, D5, D6, D7, D8, D9, D10, D11, T1, T2, T3, T4, } \\
\text { T5, T6, T7, T8, T9, T10. }\end{array}$ & 37 \\
\hline $\begin{array}{l}\text { Transformação da } \\
\text { realidade }\end{array}$ & $\begin{array}{l}\text { A2, A4, A5, A6, A7, A8, A9, A11, A13, A14, A15, A16, D2, D3, D4, } \\
\text { D5, D7, D8, D9, D10, D11, T1, T2, T4, T5, T6, T7, T8, T9, T10. }\end{array}$ & 30 \\
\hline Dimensão gnosiológica & $\begin{array}{l}\text { A1, A4, A5, A7, A9, A15, A16, D2, D3, D4, D6, D8, D9, D10, D11, T1, } \\
\text { T2, T4, T5, T6, T7, T8, T9, T10. }\end{array}$ & 24 \\
\hline Dimensão metodológica & $\begin{array}{l}\text { A3, A4, A5, A6, A7, A9, A13, A15, D4, D7, D8, D11, T1, T4, T6, T7, } \\
\text { T9, T10. }\end{array}$ & 19 \\
\hline
\end{tabular}

Fonte: Elaborado pelos autores.

A partir da distribuição de menções nos trabalhos, foi possível tecer algumas considerações. Em primeiro lugar, notamos que o aspecto mais abordado do referencial freireano, neste recorte, foi o aspecto ontológico - presente na totalidade daqueles. Ou seja, as discussões de Freire sobre as atitudes dos indivíduos ou de sua inter-relação são bem difundidos e apropriados nestes trabalhos relacionados à formação de professores e a prática de sala de aula. Compreendemos que isso pode ter sido propiciado principalmente pela maneira como Freire desenvolve suas ideias em certas obras. Por exemplo, em obras como "Cartas a Guiné-Bissau" (FREIRE, 1978); "Pedagogia da autonomia" (Idem, 2014); "Pedagogia da indignação" (Idem, 2000); "Professora sim, tia não" (Idem, 1997) é notória a forma como Freire se dirige ao educador, partilhando a sua maneira de compreender uma boa prática educativa, a partir do gênero de cartas pedagógicas. Acreditamos que esta retórica utilizada pelo autor incentive estudiosos de seu referencial a também direcionarem seus olhares à maneira como os sujeitos atuam.

Ainda assim, vimos que Freire também foi resgatado pelos autores para refletir sobre a natureza do conhecimento em si. Novamente, retomamos a ressalva já descrita acima, sobre a incapacidade de alienar dimensões gnosiológica e ontológica, para Freire. Ao contrário, o autor considera a subjetividade como parte integrante do próprio conhecimento - e por isso valoriza tanto o compartilhamento de saberes. Dito isso, essa categoria abarcou inserções que centravam-se prioritariamente na natureza do conhecimento, em primeiro plano, ainda que a subjetividade do mesmo pudesse estar também presente. Acreditamos que, justamente por essa impossibilidade, na perspectiva freireana, de separar sujeito cognoscente e objeto cognoscível, houve pouco mais de $2 / 3$ dos trabalhos abordando este aspecto: 24 de 37 publicações

A categoria metodológica, por sua vez, se fez presente em 19 dos 37 trabalhos analisados; metade dos mesmos. Pela leitura dos mesmos, consideramos que isso é consequência do próprio distanciamento do trabalho direto de Freire com o Ensino de Ciências (EC) e mesmo da modalidade regular da Educação Formal. Como aponta Lima 
(2014), Paulo Freire teve grande parte da sua experiência profissional relacionada à alfabetização de adultos trabalhadores; seja no Brasil, seja no exterior. Neres e Gehlen (2018) apontam que Freire surge como pressuposto teórico para o EC intermediado por propostas metodológicas elaboradas por outros autores da área: Delizoicov, Angotti, Pernambuco, Saul, dentre outros. De fato, o aspecto de teor mais metodológico de alguns trabalhados analisados apoiou-se em outras referências, como a Abordagem Temática Freireana (GEHLEN et al., 2014; ROSO et al., 2015; NERES; GEHLEN, 2018), Práxis Curricular via Tema Gerador (GEHLEN et al., 2014), Abordagem CTS (PINTO; MACIEL, 2014; ROSO et al., 2015), Experimentação (WEBER et al., 2012; GONÇALVES et al., 2019), Jogos Didáticos (BRITO et al., 2012), Aprendizagem por Projetos (NICOLODI; SILVA, 2016) ou mesmo a Aprendizagem Significativa (COSTA JUNIOR et al., 2019). Neste contexto, a concepção freireana surgia como princípio orientador em um nível mais basilar das propostas, indiretamente presente nas metodologias de pesquisa dos diferentes trabalhos.

Por fim, julgamos importante ter discriminado a defesa explícita com a transformação da realidade na última categoria. Como dito anteriormente, compreendemos que este elemento é essencial na Pedagogia Libertadora, e em todas as correntes pedagógicas que se reconhecem como críticas. Por outro lado, percebemos que em alguns casos a discussão sobre a superação das opressões, da condição de dominação, o compromisso com a emancipação, e outras manifestações de uma perspectiva transformadora ficam implícitos ou não se manifestam em alguns trabalhos. Tal constatação é evidenciada, neste recorte, a partir dos trabalhos com menções classificadas nesta categoria (30 entre os 37 trabalhos). Ressaltamos mais uma vez: não há como compreender todas as discussões de Freire, seja em relação à natureza do conhecimento, à natureza do sujeito, ou dos processos educativos, sem vislumbrar seu compromisso com a transformação social. É marcante que boa parte dos trabalhos analisados trouxeram esse compromisso explícito. Por outro lado, nos parece que algumas releituras e recortes sobre autor deixaram implícito ou se distanciaram desta dimensão crítica.

Como exemplo, podemos citar os conceitos de Problematização e Dialogicidade. Em alguns trabalhos, principalmente por estarem relacionadas ao Ensino de Ciências da Natureza, parecem interpretar a problematização simplesmente como elaboração ou resolução de problemas (por vezes numa perspectiva mecanicista, pragmática ou de racionalidade técnico-instrumental). Freire (2011), ao contrário, considera que a Problematização diz respeito especificamente ao desvelamento das situações-limites dos sujeitos, ou seja, sua condição de opressão. Já a Dialogicidade é por diversas vezes apropriada em trabalhos como mero diálogo, a simples relação comunicativa entre sujeitos. Em contrapartida, Freire (2011) vê na Dialogicidade o principal meio de desvelar as situações-limite problematizadas, bem como teorizá-las e decodificá-las (após o 
processo de codificação nos Círculos de Cultura), para que se possa buscar a superação de tais situações-limite, via práxis. Se por um lado, tanto a Problematização como a Dialogicidade são partes integrantes do processo de libertação para Freire, por outro, nos parece ocorrer um certo reducionismo ou operacionalização destas ações, em algumas apropriações pontuais do referencial freireano.

\section{Considerações finais}

A partir do levantamento bibliográfico realizado, pudemos tecer as seguintes considerações referentes a este recorte espacial e temporal de publicações voltadas à formação de professores das diversas ciências da natureza. Acerca da profundidade da apropriação da perspectiva freireana, concluímos que metade dos artigos analisados trouxe até 5 menções ao autor, em alguns casos chegando apenas a uma única citação. Além disso, 10 das 37 publicações se ativeram a 1 ou 2 categorias elaboradas nesta análise.

Outros levantamentos mais amplos (VIVEIRO et al., 2015; ZANCUL et al., 2015; ZANCUL; VIVEIRO, 2017, 2019; PIERONI et al., 2019), que dialogam com o presente trabalho, evidenciaram de 60 a 115 artigos embasados em Freire, publicados em revistas específicas da área de EC e Educação Ambiental, a partir de 2008. Além disso, segundo levantamento de Green (2016) à London School of Economics and Political Science, a obra Pedagogia do Oprimido foi a terceira obra mais citada no mundo, na área das ciências humanas. Portanto, notamos uma disparidade entre as referências a Freire em sua totalidade, em contraposição aos recortes do EC da formação de professores desta área.

Ainda em relação às categorias, evidenciamos que o referencial freireano foi mais relacionado à dimensão ontológica (natureza dos sujeitos) neste recorte. Todas as obras trouxeram discussões de Freire referente às atitudes e valores humanos. Consideramos que isso é reflexo da própria abordagem do autor, que em diversos momentos costuma focalizar suas falas e reflexões à própria ação dos sujeitos cognoscentes. Freire, como defensor de um posicionamento crítico e humanista, enxerga na atividade ativa e coletiva das pessoas o principal meio de superação das condições de dominação vivenciadas.

Já as discussões de Freire sobre a natureza do conhecimento em si encontraramse presente em menor escala (em 24 das 37 das obras selecionadas). Consideramos que essa menor presença se relaciona com a própria perspectiva dialética do autor, que compreende que objeto cognoscível é inseparável de sujeito cognoscente, bem como de sua historicidade e contextualização (FREIRE, 2011). Além disso, Freire costuma direcionar seus escritos a educadores e educandos, focalizando nas suas posturas (FREIRE, 1978, 1992, 2000, 2007, 2011, 2014). Assim, foram poucos os casos que as obras levantadas discutiram alguma dimensão gnosiológica isolada da ontológica. 
Por outro lado, a dimensão metodológica do pensamento freireano esteve presente em metade dos trabalhos. Neste recorte, notamos que 19 dentre as 37 publicações que incluíram metodologias pedagógicas freireanas de fato. Consideramos que isso se deve ao fato de que Freire tem o cerne de sua experiência em áreas mais distantes do EC em modalidade regular (LIMA, 2014). Por outro lado, diferentes autores desenvolveram metodologias para o EC baseadas no pressuposto freireano (GEHLEN et al., 2014). Assim, os trabalhos da área de EC levantados, em sua maioria, traziam Freire como fundamentação em nível mais basilar, enquanto buscavam outros referenciais para procedimentos pedagógicos: Abordagem Temática Freireana, Abordagem CTS, Experimentação, Aprendizagem por Projetos, Jogos Didáticos. Mesmo assim, a orientação por princípios freireanos - de dialogicidade, autonomia, problematização, compromisso com a transformação do mundo, visão dialética e crítica acerca dos conhecimentos - esteve presente nas pesquisas, de maneira positiva.

Por fim, buscamos explicitar na categoria de Transformação da realidade o grau de aproximação das publicações com a essência da Educação Libertadora: o desvelamento e superação das condições de opressão. Apesar de esta essência ser inalienável da perspectiva freireana, foi possível notar que alguns trabalhos não explicitaram seu viés emancipatório. Por um lado, grande parte dos trabalhos (30 dos 37) abordaram abertamente o compromisso com a libertação, enquanto alguns não o fizeram. Atentamos ao risco de não se explicitar tal essência, pois é possível que - não só nas publicações acadêmicas mas no próprio cotidiano pedagógico - haja um reducionismo ou distorção de ideias freireanas compromissadas com a emancipação. Citamos, por exemplo, o próprio diálogo e a problematização. Enquanto aquele pode às vezes ser tratado como a mera comunicação, esta pode ser também entendida como simples resolução operacional de problemas. Ressaltamos que é imprescindível que em qualquer vertente crítica de educação (freireana ou outras), nunca podemos perder de vista o viés intrinsecamente libertador e transformador que permeia as mesmas. É significativo ressaltar que boa parte dos trabalhos trazem explicitamente estes valores, ainda mais na área de Ensino de Ciências da Natureza, que pode em certos casos recair em uma visão positivista - de falsa neutralidade - sobre os conhecimentos científicos. Freire considera importante que os conhecimentos sejam mobilizados de forma crítica, comprometidos com a investigação e superação coletiva das situações-limite:

E não se diga que, se sou professor de biologia, não posso me alongar em considerações outras, que devo apenas ensinar biologia, como se o fenômeno vital pudesse ser compreendido fora da trama histórico-social, cultural e política. Como se a vida, a pura vida, pudesse ser vivida de maneira igual em todas as suas dimensões na favela, no cortiço ou numa zona feliz dos "Jardins" de São Paulo. Se sou professor de biologia, obviamente, devo ensinar biologia, mas, ao fazê-lo, não posso secioná-la daquela trama. (FREIRE, 1992, p. 40)

Assim, concluímos e defendemos que seja cada vez mais necessária e urgente a aproximação das ideias de Paulo Freire, bem como de vertentes críticas como um todo, 


\section{-Revista de Iniciação à Docência, v.6, n.2, 2021- Publicação: dezembro, 2021 - ISSN 2525-4332}

da área do EC, justamente por estar fortemente atrelado (tanto no senso comum como no ensino tradicional) a um viés de racionalidade técnico-instrumental, o que Freire (2011) denota como Educação Bancária. De maneira alguma Freire nega a importância da ciência, da técnica e da tecnologia. Entretanto, o autor se contrapõe a uma dicotomização baseada em percepções orientadas por um Determinismo Tecnológico em que a técnica e tecnologia são vistas como instrumentos autônomos e neutros, condicionantes da história e da sociedade; de forma positiva ou negativa (CORRÊA; GEREMIAS, 2015). Freire enxerga a relação entre sociedade e técnica de forma dialética, criticando tal dicotomia:

[...] pensando, ingenuamente, que existe o dilema humanismo-tecnologia. E, respondendo ao desafio do falso dilema, opta pela técnica, considerando que a perspectiva humanista é uma forma de retardar as soluções mais urgentes. $O$ erro desta concepção é tão nefasto como o erro da sua contrária - a falsa concepção do humanismo, que vê na tecnologia a razão dos males do homem moderno. E o erro básico de ambas, que não podem oferecer a seus adeptos nenhuma forma real de compromisso, está em que, perdendo elas a dimensão da totalidade, não percebem o óbvio: que humanismo e tecnologia não se excluem. Se o meu compromisso é realmente com o homem concreto, com a causa de sua humanização, de sua libertação, não posso por isso mesmo prescindir da ciência, nem da tecnologia, com as quais me vou instrumentando para melhor lutar por esta causa. Por isso também não posso reduzir o homem a um simples objeto da técnica, a um autômato manipulável. (FREIRE, 2007, p. 22)

Além disso, se faz mais urgente ainda que ocorra esta aproximação à formação inicial de professores, por se tratar de um importante momento de construção da prática docente. Segundo Freire (2014, p. 87):

É interessante observar que a minha experiência discente é fundamental para a prática docente que terei amanhã ou que estou tendo agora simultaneamente com aquela. É vivendo criticamente a minha liberdade de aluno ou aluna que, em grande parte, me preparo para assumir ou refazer o exercício de minha autoridade de professor. Para isso, como aluno de hoje que sonha com ensinar amanhã ou como aluno que já ensina hoje devo ter como objeto de minha curiosidade as experiências que venho tendo com professores vários e as minha própria, se as tenho, com meus alunos. (FREIRE, 2014, p. 87)

Em suma, após realizar este breve levantamento bibliográfico do recorte específico de formação inicial de professores de ciências da natureza, interseccionado com a perspectiva freireana, concluímos que há nas pesquisas diversas contribuições para a formação docente. Estas possuem um grande potencial de se projetarem e refletirem na prática educativa na área de Ensino de Ciências da Natureza. Dessa maneira, é possível contribuirmos para desconstrução de vieses mais ingênuos e idealizados das ciências da natureza, como a visão absoluta, neutra, alienada, técnico-instrumental, que permeia a área. Assim, consideramos necessária a intensificação e aprofundamento da exploração da perspectiva freireana nesta área de formação de professores. 


\section{Referências}

ALTARUGIO, Maisa Helena; VARONE, María Cándida. Sociodrama pedagógico: uma proposta para a tomada de consciência e reflexão docente. Alexandria: Revista de Educação em Ciência e Tecnologia, v. 9, n. 1, p. 31-55, 2016.

ALTMANN, Helena. Influências do Banco Mundial no projeto educacional brasileiro. Educação e pesquisa, v. 28, n. 1, p. 77-89, 2002.

ARAÚJO, Wanna Santos. Uma prática dialógica com aproximações da educação CTS: propostas emancipatórias no estágio dos licenciandos em ciências biológicas. 2018. Tese (Doutorado em Educação) - Faculdade de Educação, Universidade de Brasília, Brasília, 2018.

BARCELLOS, Marcília Elis, SOUSA, Elisabeth Gonçalves de; FONTANA, Laura Roberta; TOLEDO, Soraia Wanderosck, BRAGA JUNIOR, Celso. A reforma do ensino médio e as desigualdades no Brasil. Revista brasileira da educação profissional e tecnológica, v. 2, n. 13, p. 118-136, 2017.

BARDIN, Laurence. Análise de conteúdo. Tradução de Luís Antero Reto e Augusto Pinheiro. Lisboa: Edições 70, 1977.

BASTOS, Fernando et al. Considerações sobre dificuldades enfrentadas por professores de ciências e matemática em seu cotidiano de trabalho. Anais... VIII ENPEC, 2011.

BOURDIEU, Pierre. A escola conservadora: As desigualdades frente à escola. In: Escritos de educação. Petrópolis, RJ: Vozes, 1998.

BRASIL. Ministério da Educação. Coordenação de Aperfeiçoamento de Pessoal de Ensino Superior. Portal de Periódicos CAPES/MEC, 2020. Disponível em: <http://www-periodicoscapes-gov-br.ezl.periodicos.capes.gov.br/index.php?> Acesso em 10 jan. 2020.

BRASIL. Ministério da Ciência, Tecnologia e Inovações. Instituto Brasileiro de Informações em Ciência e Tecnologia. Biblioteca Digital Brasileira de Teses e Dissertações, 2020. Disponível em: <https://bdtd.ibict.br/vufind/> Acesso em 10 jan. 2020.

BRITO, Lya Christina da Costa et al. Avaliação de um minicurso sobre o uso de jogos no ensino. Revista Brasileira de Pós-Graduação, v. 8, n. 2, 2012.

CARDOSO, Danilo. Mídia, Ciência e Ensino: Problematizações na formação inicial de Professores de Física. 2019. Tese (Doutorado em Ensino de Ciências) - Instituto de Física, Instituto de Química, Instituto de Biociências, Faculdade de Educação, Universidade de São Paulo, São Paulo, 2019.

CARLOMAGNO, Márcio; ROCHA, Leonardo Caetano da. Como criar e classificar categorias para fazer análise de conteúdo: uma questão metodológica. Revista Eletrônica de Ciência Política, v. 7, n. 1, 2016.

CHASTEEN, John Charles. Born in blood and fire: a concise history of Latin America. 4. ed. Nova lorque: W.W. Norton \& Company, 2016.

CONTRERAS, José. A autonomia de Professores. São Paulo: Cortez, 2002.

CORRÊA, Raquel Folmer; GEREMIAS, Bethania Medeiros. Determinismo Tecnológico: 
elementos para debates em perspectiva educacional. Tecnologia e Sociedade, v. 9, n. 18, 2013.

COSTA JUNIOR, José de Oliveira et al. Paisagens sonoras, música e indústria cultural: problematização na formação inicial de professores de física. Góndola, enseñanza y aprendizaje de las ciencias, v. 14, n. 2, p. 322-339, 2019.

CUNHA, Fátima Suely Ribeiro. A pesquisa na formação inicial de professores de ciências no Timor-Leste: contribuições do Grupo de Estudos sobre Ensino de Ciências e Tecnologia (GEECITE). 2017. Tese (Doutorado em Educação Científica e Tecnológica) - Centro de Ciências Físicas e matemáticas, Centro de Ciências da Educação, Centro de Ciências Biológicas, Universidade Federal de Santa Catarina, 2017.

DALMOLIN, A. M. T. À sombra deste jacarandá: articulações entre ciências da natureza e educação do campo na formação docente. 2020. Tese (Doutorado em Educação em Ciências) - Instituto de Ciências Básicas da Saúde, Universidade Federal do Rio Grande do Sul, Porto Alegre, 2020.

DUARTE, Newton. Conhecimento tácito e conhecimento escolar na formação do professor (por que Donald Schön não entendeu Luria). Educação \& Sociedade, v. 24, n. 83, p. 601-625, 2003.

FERREIRA, Elízio Mário. Um olhar sobre as atividades de formação em um curso de licenciatura em química. 2015. Dissertação (Mestrado Profissional em Ensino de Ciências) - Instituto de Ciências Exatas e Biológicas, Universidade Federal de Ouro Preto, Ouro Preto, 2015.

FREIRE, Paulo. Cartas a Guiné Bissau: registros de uma experiência em processo. Rio de Janeiro: Paz e Terra, 1978.

FREIRE, Paulo. Educação e mudança. Rio de Janeiro: Paz e Terra, 2007.

FREIRE, Paulo. Pedagogia da autonomia: saberes necessários à prática educativa. Rio de Janeiro: Paz e Terra, 2014.

FREIRE, Paulo. Pedagogia da esperança: um reencontro com a Pedagogia do Oprimido. Rio de Janeiro: Paz e Terra, 1992.

FREIRE, Paulo. Pedagogia da indignação: cartas pedagógicas e outros escritos. São Paulo: Editora UNESP, 2000.

FREIRE, Paulo. Pedagogia do oprimido. Rio de Janeiro: Paz e Terra, 2011.

FREIRE. Paulo. Professora sim, tia não: cartas a quem ousa ensinar. São Paulo: Olho d’Água, 1997.

FREITAS, Marcos Cesar; BICCAS, Maurilane de Souza. História social da educação no Brasil (1926 - 1996). São Paulo: Cortez, 2009.

GEHLEN, Simoni Tormöhlen et al. A inserção da abordagem temática em cursos de licenciatura em física em instituições de ensino superior. Investigações em Ensino de Ciências, v. 19, n. 1, p. 217-238, 2016.

GIMENES, Camila Itikawa. O Programa Institucional de Bolsa de Iniciação à Docência 
(PIBID) e a formação de professores de Ciências Naturais: possibilidade para a práxis na formação inicial? 2016. Tese (Doutorado em Educação) - Faculdade de Educação, Universidade de São Paulo, São Paulo, 2016.

GONDIM, Maria Stela da Costa. A história de um bordado: saberes populares como temas geradores de uma educação CTS na formação de professores de química. 2019. Tese (Doutorado em Educação) - Faculdade de Educação, Universidade de Brasília, Brasília, 2019.

GONÇALVES, Fábio Peres et al. As transformações e as permanências de conhecimentos sobre atividades experimentais em um contexto de formação inicial de professores de química. Investigações em Ensino de Ciências, v. 24, n. 3, 2019.

GREEN, Elliot. What are the most-cited publications in the social sciences (according to Google Scholar)? London School of Economics and Political Science, 2016. Disponível em: http://eprints.Ise.ac.uk/66752/1/_Ise.ac.uk_storage_LIBRARY_Secondary_libfile_shared_r epository_Content_LSE\%20Impact\%200f\%20Soc\%20Sci\%20blog_2016_May_What\%20are\%2 othe\%2omost-

cited\%20publications\%20in\%20the\%20social\%20sciences\%20according\%20to\%20Google\%20S cholar.pdf. Acesso em 7 mar. 2021.

GUAITA, Renata Isabelle. As atividades experimentais mediadas por novas tecnologias da informação e comunicação em licenciaturas em ciências da natureza: situação-limite e inédito viável. 2015. Dissertação (Mestrado em Educação Científica e Tecnológica) Centro de Ciências Físicas e Matemáticas, Centro de Ciências da Educação, Centro de Ciências Biológicas, Universidade Federal de Santa Catarina, Florianópolis, 2015.

LEITE, Vanessa Carneiro. Educação problematizadora de Paulo Freire na perspectiva de licenciandos em química. 2015. Tese (Doutorado em Química) - Instituto de Química, Universidade Federal de Goiás, Goiânia, 2015.

LEMES, Sebastião de Souza. O currículo para a escola democratizada: das pistas históricas às perspectivas necessárias. In: COLVARA, Laurence Duarte (Coord.). Caderno de Formação: formação de professor: Gestão Escolar, v. 2. São Paulo: Cultura Acadêmica, Universidade Estadual Paulista, Univesp, 2013. p. 170-181,

LIBÂNEO, José Carlos. O dualismo perverso da escola pública brasileira: escola do conhecimento para os ricos, escola do acolhimento social para os pobres. Educação e Pesquisa, v. 38, n. 1, p. 13-28, 2012.

LIMA, Daniele Dorotéia et al. Histórias de professores na Amazônia: marcas de um contexto na formação do PARFOR. Revista Cocar, v. 14, n. 28, p. 420-439, 2020.

LIMA, Gislaine Rocha de; FERREIRA, Maria Aparecida dos Santos. A formação docente e o PIBID-subprojeto de Biologia do IFRN/Macau: uma interlocução entre a formação inicial e continuada. HOLOS, v. 2, p. 318-332, 2018.

LIMA, Paulo Gomes. Uma leitura sobre Paulo Freire em três eixos articulados: o homem, a educação e uma janela para o mundo. Pro-Posições, Campinas, v. 25, n. 3, p. 63-81, dez. 2014 .

MACKEIVICZ, Osmar. Concepções de ensino elaboradas pelos acadêmicos das 
licenciaturas. 2017. Dissertação (Mestrado em Educação) - Setor de Ciências Humanas, Letras e Artes, Universidade Estadual de Ponta Grossa, Ponta Grossa, 2017.

MARCÍLIO, Maria Luiza. História da escola em São Paulo e no Brasil. São Paulo: Imprensa Oficial do Estado de São Paulo: Instituto Fernand Braudel, 2005.

MARTINS, Danielle Juliana Silva. As repercussões do Programa Institucional de Bolsa de Iniciação à Docência do Instituto Federal de Educação Ciência e Tecnologia do Sertão Pernambucano para a formação inicial do docente. 2016. Dissertação (Mestrado em Ensino) - Centro Universitário UNIVATES, Lajeado, 2016.

MELO, Marcos Gervânio de Azevedo. Jogo Tríptico na formação inicial do professor de ciências: uma proposta de ensino de Física sob o enfoque CTS que busca promover ACT. 2019. Tese (Doutorado em Ensino de Ciência e Tecnologia) - Universidade Tecnológica Federal do Paraná, Ponta Grossa, 2019.

MORAIS, João Kaio Cavalcante de; ALBINO, Giovana Gomes. Formação inicial de professores de biologia no IFRN: a concepção dos licenciandos sobre o ensino/ensinar. HOLOS, v. 5, p. 231-241, 2015.

MOREIRA, Antônio Flávio Barbosa. Currículo e controle social. Teoria e Educação, n. 5, p. 41-54, 1992.

MORI, Lorraine. Problemas e problematização no ensino de química: um estudo com graduandos de universidades do oeste do Paraná. 2019. Dissertação (Mestrado em Educação) - Centro de Educação, Comunicação e Artes, Universidade Estadual do Oeste do Paraná, Cascavel, 2019.

NARDI, Roberto; CORTELA, Beatriz Salemme Correa. Formação inicial de professores de física: novas diretrizes, antigas contradições. In: CORTELA, Beatriz Salemme Correa

(Org.). Formação de professores de Física em universidades públicas: estudos realizados a partir de reestruturações curriculares. São Paulo: Livraria da Física, 2015. p. 3-24.

NERES, Cleide Aguiar; GEHLEN, Simone Tormöhlen. Investigação Temática na Formação de Professores: Indicativos da Pesquisa em Educação em Ciências. Revista Brasileira de Pesquisa em Educação em Ciências, [S. I.], v. 1, n. 2, p. 239-267, 2018.

NICOLODI, Suzana Cini Freitas; SILVA, Valentim da. Formação de professores e formação humana: não é só necessária, mas possível. Educar em Revista, n. 61, p. 107-126, 2016.

NOGUEIRA, Keysy Solange Costa. Reflexos do Pibid na prática pedagógica de licenciandos em química envolvendo o conteúdo oxirredução. 2018. Tese (Doutorado em Ensino de Ciências) - Instituto de Física, Instituto de Química, Instituto de Biociências, Faculdade de Educação, Universidade de São Paulo, São Paulo, 2018.

OLIVEIRA, Quitéria Costa de Alcântara. Formação docente: saberes mobilizados e produzidos no contexto do estágio supervisionado do instituto federal. 2016. Dissertação (Mestrado Profissional em Educação) - Faculdade de Educação, Universidade de Brasília, Brasília, 2016.

PIERONI, Laís Goyos; ZANCUL, Maria Cristina De Senzi; VIVEIRO, Alessandra Aparecida. Paulo Freire na produção científica brasileira sobre Ensino de Ciências e Educação Ambiental (2010-2014). In: MEMBIELA, Pedro et al. (Eds). Nuevos retos en la enseñanza 
de las ciencias. Ourense: Educación Editora, 2019. p. 475-480.

PINTO, José Antônio; MACIEL, Maria Delourdes. Discussão e Debate de Questões CTS por Alunos do Último Ano de um Curso de Licenciatura em Química: Definições de Ciência e Tecnologia. HOLOS, v. 1, p. 247-257, 2014.

REZENDE, Flavia; OSTERMANN, Fernanda. Hegemonic and counter-hegemonic discourses in science education scholarship from the perspective of post-critical curricular theories. Cultural Studies of Science Education, p. 1-19, 2020.

RIGUE, Fernanda Monteiro. Uma genealogia da formação inicial de professores de química no Brasil. 2020. Tese (Doutorado em Educação) - Centro de Educação, Universidade Federal de Santa-Maria, Santa Maria, 2020.

ROBERTS, P. Paulo Freire. Oxford Research Encyclopedia of Education. Disponível em: https://oxfordre.com/education/view/10.1093/acrefore/9780190264093.001.0001/acrefore9780190264093-e-10. Acesso em 3 mai. 2021.

ROSO, Caetano Castro et al. Currículo temático fundamentado em Freire-CTS: engajamento de professores de física em formação inicial. Ensaio Pesquisa em Educação em Ciências, v. 17, n. 2, p. 372-389, 2015.

SALGUEIRO, Beatriz Alves. Análise de um processo formativo de licenciandos e licenciados das ciências da natureza sobre habilidades docentes e transdisciplinaridade. 2019. Dissertação (Mestrado em Ensino de Ciências e Matemática). Universidade Federal Rural de Pernambuco, Recife, 2019.

SAVIANI, Dermeval. As concepções pedagógicas na história da educação brasileira. 2005. SAVIANI, Dermeval. Escola e democracia: teorias da educação, curvatura da vara, onze teses sobre a educação política. 35. ed. Campinas: Autores Associados, 2002.

SAVIANI, Dermeval. Formação de professores no Brasil: dilemas e perspectivas. Poíesis Pedagógica, v. 9, n. 1, p. 07-19, 2011.

SAVIANI, Dermeval. História das idéias pedagógicas no Brasil. Campinas: Autores Associados, 2007.

SGUISSARDI, Valdemar. Educação superior no Brasil. Democratização ou massificação mercantil?. Educação \& Sociedade, v. 36, n. 133, p. 867-889, 2015.

SILVA, Valdecir Manoel da. Música na formação inicial e no ensino de química: saberes, práticas e aprendizagens. 2018. Dissertação (Mestrado Profissional em Ensino de Ciências e Matemática) - Centro de Ciências e Tecnologia, Universidade Estadual da Paraíba, Campina Grande, 2018.

SILVEIRA, Marcelo Pimentel da; ZANETIC, João. Formação de professores e ensino de química: reflexões a partir do livro Serões de Dona Benta de Monteiro Lobato e da pedagogia de Paulo Freire. Alexandria: Revista de Educação em Ciência e Tecnologia, v. 9, n. 2, p. 61-85, 2016.

TADEU, Tassiéllen Soares Antunes. Sensibilizando o olhar docente através de estratégias dialógicas problematizadoras no estágio curricular em química. 2018. Dissertação (Mestrado Profissional em Ensino de Ciências) - Universidade Federal do Pampa, Bagé, 
2018.

VALA, Jorge. A análise de conteúdo. In SILVA, Augusto Santos; PINTO, José Madureira (Orgs.). Metodologia das Ciências Sociais, p. 101-128. [s.d.]

VARGAS, Ghisiani Spinelli. Uma abordagem do tema estruturante Matéria e Radiação no Curso Normal: a busca da criticidade na formação de professores para os anos iniciais do Ensino Fundamental. 2018. Dissertação (Mestrado Profissional em Ensino de Física) Instituto de Física, Universidade Federal do Rio Grande do Sul, Porto Alegre, 2018.

VIEIRA, Edimara Fernandes. Histórias em quadrinhos na formação inicial de professores de física: da curiosidade à elaboração de sentidos. 2018. Dissertação (Mestrado em Ensino de Ciências) - Instituto de Física, Instituto de Química, Instituto de Biociências, Faculdade de Educação, Universidade de São Paulo, São Paulo, 2018.

VIVEIRO, Alessandra Aparecida et al. A apropriação da obra de Paulo Freire na produção científica em ensino de Ciências (2010-2014). In: X Encontro Nacional de Pesquisa em Educação em Ciências, 2015, Águas de Lindóia. Anais..., 2015.

WATANABE-CARAMELLO, Giselle et al. Desafios e possibilidades para a abordagem de temas ambientais em aulas de Física. Revista Brasileira de Pesquisa em Educação em Ciências, v. 12, n. 1, p. 205-222, 2012.

WEBER, Karen Cacilda et al. Vivenciando a prática docente em Química por meio do Pibid: introdução de atividades experimentais em escolas públicas. Revista Brasileira de PósGraduação, v. 8, n. 2, 2012.

ZANCUL, Maria Cristina de Senzi. et al. A obra de Paulo Freire na produção científica em educação ambiental (2010-2014). In: XV Encontro Paranaense de Educação Ambiental, 2015, Guarapuava. Anais..., 2015.

ZANCUL, Maria Cristina de Senzi; VIVEIRO, Alessandra Aparecida. Paulo Freire em produções científicas sobre formação de professores para o ensino de ciências (20102014). Enseñanza de las ciencias: revista de investigación y experiencias didácticas, $n$. Extra, p. 3075-3080, 2017.

ZANCUL, Maria Cristina de Senzi; VIVEIRO, Alessandra Aparecida. Paulo Freire em pesquisas sobre a prática pedagógica no ensino de ciências: um panorama de publicações em periódicos ibero-americanos (2008-2017). In: MACEDO, Beatriz et al. Enseñaza y Aprendizaje de las Ciencias em Debate. v. 3. Alcalá de Henares: Universidad de Alcalá/Servicio de Publicaciones, 2019. 